Preprint. Final version appears as:

Morgan, R.M, Little, M., Gibson, A., Hicks, L., Dunkerley, S. \& Bull, P.A. (2008)

The preservation of quartz grain surface textures following vehicle fire and their use

in forensic enquiry. Science and Justice. DOI 10.1016/j.scijus.2008.04.001

\title{
The preservation of quartz grain surface textures following vehicle fire and their use in forensic enquiry
}

Morgan, R. M. ${ }^{1}$, Little, M. ${ }^{2}$, Gibson, A. ${ }^{2}$, Hicks, L. ${ }^{2}$, Dunkerley, S. ${ }^{2}$ and Bull, P. A. ${ }^{2}$

${ }^{1}$ UCL Jill Dando Institute of Crime Science, 35 Tavistock Square, London WC1H 9EZ

${ }^{2}$ Oxford University Centre for the Environment, University of Oxford, South Parks Road, Oxford, OX1 3QY

Communicating author: Ruth Morgan

Ruth.morgan@ucl.ac.uk

Tel: +442031083037

Fax: +442031083088 


\title{
The preservation of quartz grain surface textures following vehicle fire and their use in forensic enquiry
}

Morgan, R. M. ${ }^{1}$, Little, M. ${ }^{2}$, Gibson, A. ${ }^{2}$, Hicks, L. ${ }^{2}$, Dunkerley, S. ${ }^{2}$ and Bull, P. A. ${ }^{2}$

\begin{abstract}
During a terrorist trial, dispute arose as to whether the temperature produced in a car fire was sufficient to destroy quartz grain surface textures. A series of seven sequential experiments showed that the temperature for quartz surface texture modification/destruction and the production of vugs, vesicles and glassy precipitation ('snowdrifting') occurred at $1200^{\circ} \mathrm{C}$ under normal atmospheric conditions. By adding a number of man-made and natural substances, it was found that only the presence of salts depressed this modification temperature (to $900^{\circ} \mathrm{C}$ ). Experiments to determine the temperature of fire in a car indicated that the maximum temperature produced under natural conditions $\left(810^{\circ} \mathrm{C}\right)$ was insufficient to affect the quartz grain surface textures. These results confirm the use of surface texture analysis of quartz grains recovered from the remains of cars subjected to fire and their use as a forensic indicator.
\end{abstract}

Keywords: Forensic science, quartz, vehicle fire temperatures, scanning electron microscopy. 


\section{Background}

During a trial involving a terrorist attack, the prosecution presented, as part of their evidence, the results from quartz grain surface texture analysis of various soils from the attack scene and from associated comparator sites. Some of these quartz grains had been recovered from a vehicle which had been completely destroyed by fire, and consequently no other physical evidence (such as DNA, fibres, pollen etc.) could be recovered. The defence argued that this geological evidence should be disregarded, claiming that the temperatures experienced during the fire would have caused the surviving quartz grains to become so heavily fractured and altered that their surface characteristics would no longer be recognisable. This paper therefore, sets out to determine under what conditions quartz grain surface textures can be preserved after exposure to the temperatures associated with vehicular fire.

\section{Introduction}

Quartz is a highly resistant and therefore, a ubiquitous mineral found in most soil/sediment samples. It has been shown to demonstrate a range of clearly identifiable and environmentally specific surface textures [1-5] containing texture assemblages which form specific grain types [6-9]. Recent studies show the relevance of this technique as a 'fingerprinting mechanism' useful in the forensic arena [10].

Soil/sediment samples have been analysed and compared for forensic purposes by a number of methods including colour [11-12], organic content [13], biological characteristics [14-16], particle size analysis [17-20] and mineralogy [21]. However, the action of fire will have a profound influence on the viability of all these measurable characteristics of soil as significant modifications to these characteristics occur. Colour and particle size distributions of a soil have been shown to be modified at $400^{\circ} \mathrm{C}[22,23]$, as have mineralogy [24] and soil/sediment chemistry [25]. Heating initially affects the biological activity of a soil/sediment, while intermediate temperatures from sustained heating can implement appreciable chemical changes. When temperatures reach sufficient levels, permanent physical alterations occur (as outlined in figure 1 [26]). 
Fires and their associated high temperatures can therefore, have a multitude of impacts on the chemical, physical and biological characteristics of a soil/sediment sample rendering many of the traditional analytical techniques employed in forensic analysis impracticable under these conditions. It has however, been observed that after severe burning quartz, mica and feldspar grains survived [23]. It is therefore important to know whether the quartz grain surface textures are modified or altered after exposure to high temperatures rendering this technique equally unusable in the situations such as that found in vehicle fires.

This paper presents a series of experiments which have been undertaken to assess the impact of temperature on quartz grain surface textures, and to offer conclusions in the light of this work as to the practicability of this analytical technique for forensic soil/sediment samples that have been subjected to high temperature environments. The experiments involve ascertaining the critical temperature for quartz grain surface modification, whether this critical temperature varies according to different types of quartz and whether it varies in the presence of other materials normally associated with vehicles and soils (catalysts or inhibitors).

\section{Experimental Work}

\subsection{Experiment 1}

The aim of this experiment was to observe the critical temperature of quartz surface texture modification under normal atmospheric conditions using heat generated from a muffle furnace. Four samples were used which comprised of two types of soil and two types of sand (Soils A and B taken from Oxfordshire and Coventry respectively, aquarium sand (sand C), and Chilean coastal dune sand (sand D)). These different types were chosen because of their varied origin and hence their varied characteristics. A control sample from each type of soil and sand was cleaned by boiling $5 \mathrm{~g}$ of each sample in a test tube with sodium-hexametaphosphate, followed by washing with distilled water (for cleansing and the removal of soluble salts) and repeating the process with $10 \%$ hydrocholoric acid. The sample was then dried in an oven at $40^{\circ} \mathrm{C}$ and gently disaggregated. Medium sand-sized quartz grains were then 
selected and one hundred of these 'control' grains from each sample were analysed using the scanning electron microscope (SEM). Characteristic surface texture features were noted and grain types established [10].

One gram of each sample was then taken and heated in a high-heat tolerant aluminosilica crucible at $900^{\circ} \mathrm{C}$ for 30 minutes in a muffle furnace. The soil samples were washed to remove any charred debris, and 30 quartz grains extracted and mounted on SEM aluminium stubs for surface texture analysis. This procedure was also repeated on samples which were heated to $1200^{\circ} \mathrm{C}$.

The surface textures of the quartz grains in samples A, B and C which were heated to $900^{\circ} \mathrm{C}$, exhibited no physical change before or after heating $(0 \%$ of the grains were modified). Chi-squared results confirmed that soils $\mathrm{A}$ and $\mathrm{B}$ and sand $\mathrm{C}$ heated at $900^{\circ} \mathrm{C}$ were not significantly different (at the $95 \%$ significance level) to the equivalent unheated samples. However, sand D was found by Chi-squared analysis to be significantly different (indeed $90 \%$ of grains were modified). In order to assess why sand D may have behaved significantly differently to samples A, B, and C at $900^{\circ} \mathrm{C}$, Dionex analysis was undertaken on the soluble constituents of soils A and B, and sand D. This test revealed a high salt content in sand D (on average 527.34ppm chloride, 56.42ppm sulphate where $\mathrm{n}=3$ ) in comparison to the other samples. The possible impact of the presence of salt is explored further in Experiments 5 and 6 of this paper.

The surface textures of the grains that were subjected to a temperature of $1200^{\circ} \mathrm{C}$ exhibited notable changes, with the appearance of vugs (figure 2), cracks [27] (figure 3 ) and glassy precipitation ('snowdrift') (figure 4). It was found that $83 \%$ of the quartz grains in soil A were modified, $60 \%$ in soil B, $93 \%$ in sand C 100\% in sand D. These identifiable changes at $1200^{\circ} \mathrm{C}$ made it impossible to identify the surface texture of the quartz grains and, in effect, rendered it impossible to determine that these altered grains contained the same characteristics as those of the control samples. Thus, at $1200^{\circ} \mathrm{C}$ all samples revealed quartz grain surface modification whilst at $900^{\circ} \mathrm{C}$ the quartz surfaces from samples A, B and C remained unmodified. Quartz from sample D did however exhibit modification at $900^{\circ} \mathrm{C}$ which may be due to an elevated salt content of the sample. 


\section{$3.2 \quad$ Experiment 2}

This experiment was formulated to test the conclusions derived from experiment 1 and to include the consideration of the effect of the introduction of denim, cotton and lycra materials as having a possible catalytic or inhibiting effect on the quartz modification critical temperature. The same procedure as used in experiment 1 was repeated on the same four sand and soil samples which were this time wrapped in material swatches.

The results of these experiments demonstrated that the addition of denim, cotton or lycra to the 30 quartz grains studied appeared to have no effect on the occurrence of modification of the quartz grain surfaces at $900^{\circ} \mathrm{C}$ and $1200^{\circ} \mathrm{C}$. The quartz grains which were heated to $900^{\circ} \mathrm{C}$ still resembled the quartz in the corresponding control sample (figures 5, 6 and 7) (none of the grains from soil A and B were modified, and only $0.01 \%$ were modified in sand C). At $1200^{\circ} \mathrm{C}$, the quartz surface textures was still shown to be statistically different (Chi-squared analysis) to the corresponding control sample (with $100 \%$ of soils A and B and sand C quartz grain surfaces modified). Sand D still demonstrated modifications at a lower temperature threshold, with $88 \%$ of quartz grain surfaces modified at $900^{\circ} \mathrm{C}$ and $100 \%$ modified at $1200^{\circ} \mathrm{C}$. In conclusion therefore, the results of experiment 1 and experiment 2 can be judged as having a similar outcome.

\subsection{Experiment 3}

Further experiments were undertaken with five additional sand samples which all had a high quartz content (soft white sand from Lochaline, West Scotland; sand from Cheltenham; sand from Storsjoen Lake, East Norway; beach sand from Douglas, Isle of Man; beach sand from Keem Bay, Archill Island, Co Mayo). These samples were used to test the possible catalytic effect of engine oil, car body paint, rubber, footwell carpet and plastic respectively. Firstly, the samples were subjected to temperatures (in a muffle furnace) at $200^{\circ} \mathrm{C}$ increments between $200^{\circ} \mathrm{C}$ and $1200^{\circ} \mathrm{C}$ to establish whether the quartz surfaces in these samples behaved similarly to previously tested 
samples (i.e. no change at $900^{\circ} \mathrm{C}$, but with modifications apparent at $1200^{\circ} \mathrm{C}$ ). Quartz surface texture analysis was carried out on the untreated 'control' grains from each sample, and the results compared with SEM analysis of the grains subjected to $200^{\circ} \mathrm{C}$, $400^{\circ} \mathrm{C}, 600^{\circ} \mathrm{C}, 800^{\circ} \mathrm{C}, 1000^{\circ} \mathrm{C}$ and $1200^{\circ} \mathrm{C}$ temperatures with a catalyst (as mentioned above).

These experiments on sand from five different sources to that used in experiments 1 and 2 confirmed that a temperature threshold of $1200^{\circ} \mathrm{C}$ does indeed exist at normal atmospheric pressures for the modification of quartz surface textures. In addition, the results of these experiments agree with the results obtained in experiment 2 that the presence of other materials, in this case engine oil, car body paint, rubber, footwell carpet and plastic, appears to have no effect on the modification of the quartz grain surface textures.

\section{$3.4 \quad$ Experiment 4}

Having established the premise that in general quartz surfaces are modified at $1200^{\circ} \mathrm{C}$ (with the exception of the marine sand in experiments 1 and 2 - for further discussion see 3.5), and that various clothing items, paints, oils and plastics have no effect upon this critical temperature, this series of experiments examined the effect of direct vehicular fire upon the sand grains. Three experimental vehicle fires were performed at Moreton in Marsh Fire Service College (in conjunction with a forensic arson investigation course) to assess their impact on quartz grain surface textures. These three scenarios involved:

1. Sierra XR4i: an engine fire started using wood and fire lighters.

2. Ford Escort: a rear seat cabin fire started using a cigarette lighter and a crisp packet.

3. Renault 5: a simulated electrical fire started in the driver's side dashboard using a fire lighter.

Sand samples (from the same sources as those used in experiment 3) were positioned within the cars in the left and right front and back footwells and the left and right front 
wheel arches. Each location had samples which had been prepared in both 'open' and 'closed' combustion boats. The closed combustion boats did not expose the quartz to naked flame, but ensured that some samples survived the blast of the fire hoses. Thermocouples were attached to the driver side footwell and left and right wheel arch of each vehicle and each thermocouple was linked to a computer in the mobile control centre which was programmed to record the temperature every three seconds for the duration of the fire. Each fire was allowed to reach a peak fire intensity and a high level of cabin destruction.

It was found that none of the simulated vehicle fires achieved the critical temperature of $1200^{\circ} \mathrm{C}$ (see figures 8 and 9). It is significant that the temperatures reached in these vehicular fires did not exceed $810^{\circ} \mathrm{C}$ when considering the use of quartz grain surface texture analysis of quartz recovered from such situations. All of the quartz grains recovered demonstrated no sign of temperature-induced modification.

\subsection{Experiment 5}

This experiment was designed to investigate whether quartz formed by different mechanisms [28], which were submitted to the same procedures and temperatures as found in the previous experiments, exhibited similar alteration patterns. Four different types of quartz (crushed pegmatitic quartz, metamorphic schist, washed aeolian-derived sand and unwashed marine sand (the latter of similar origin to sand D in experiment 1 and therefore containing a high salt content)) were exposed to temperatures in the muffle furnace of $900^{\circ} \mathrm{C}$ and $1200^{\circ} \mathrm{C}$. After SEM assessment of these initial results, further experiments were carried out (see figure 10) to assess if the length of time that the quartz grains were subjected to high temperatures, the particle size of the quartz, or the presence of salt (in the marine quartz sample) affected the modification of the quartz grain surface textures.

At $900^{\circ} \mathrm{C}$ the pegmatitic quartz, the metamorphic schist and the aeolian derived quartz showed very little (but some) evidence of surface texture modification $(0 \%, 4 \%, 0 \%$ of grains modified respectively) when compared to the corresponding untreated quartz grains. The marine quartz however displayed significant modification with $70 \%$ of 
the grains exhibiting modification such as cracks, glassy precipitation (snowdrift), and small vugs.

At $1200^{\circ} \mathrm{C}$, the metamorphic schist, washed aeolian and unwashed marine quartz all exhibited $100 \%$ modification, exhibiting features such as cracks, small vugs, glassy precipitation (snowdrift), single vesicles and large vugs (figures 2 and 7). However, only $4 \%$ of the pegmatitic quartz grains were so affected.

Due to the unexpected results encountered for the experimental run at $900^{\circ} \mathrm{C}$ for the unwashed marine quartz and at $1200^{\circ} \mathrm{C}$ for the pegmatitic quartz, further experiments were undertaken as outlined in figure 10.

The particle size of the pegmatitic quartz, and length of time of heating are not significant factors that affect the propensity of the quartz surface texture to modification at $1200^{\circ} \mathrm{C}$. However, the presence of salt in the form of sodium and magnesium chloride does appear to have an affect on quartz grain surface texture modification, as significant modification occurs to the quartz at $900^{\circ} \mathrm{C}$ when this salt is present which does not occur when it is not present (see also results for sand D in experiments 1 and 2).

\subsection{Experiment 6}

Given the observation from experiment 5 that salts do indeed seem to have the same effect of reducing the critical temperature for quartz surface texture modification (as found in experiment 1), this experiment tested whether various salt solutions of differing complexity would also affect the critical temperature for quartz grain surface texture modification.

Fresh quartz grains were produced by crushing a large intact quartz crystal (as in experiment 5). The 'control' grains were heated at $800^{\circ} \mathrm{C}, 900^{\circ} \mathrm{C}, 1000^{\circ} \mathrm{C}$ and $1100^{\circ} \mathrm{C}$, as were grains treated with sea salt solution precipitated onto the surface. This was then repeated with different types of salt (table salt $\mathrm{pH} 10.14$, sea salt $\mathrm{pH}$ 9.30, Chilean salt (from the Atacama desert) $\mathrm{pH} 6.02$ and Namibian salt (from the Namib desert) pH 6.51), at temperatures of $800^{\circ} \mathrm{C}, 900^{\circ} \mathrm{C}$ and $1000^{\circ} \mathrm{C}$. 
These results confirm the findings of experiment 5 that the presence of salt depresses the temperature at which heat-induced modifications to surface textures are generated from $1200^{\circ} \mathrm{C}$ to $900^{\circ} \mathrm{C}$. The surface textures of fresh, clean quartz crystals were not modified by temperatures up to $1100^{\circ} \mathrm{C}$, however, in the presence of salt, heatinduced surface textures of the quartz occurred at $900^{\circ} \mathrm{C}$ (see figures 11 and 12).

The quartz grains treated with table salt demonstrated the most widespread heatinduced surface texture features at $900^{\circ} \mathrm{C}$ and $1000^{\circ} \mathrm{C}$ with all the grains exhibiting glassy precipitation (snowdrifting), and all but one grain exhibiting single vesicles. At $1000^{\circ} \mathrm{C}$ the single vesicles appear to have burst to produce the extensive vesicular structure effect on $27 \%$ of the grains. The quartz treated with sea salt showed a similar pattern, but no extensive vesicular features were seen. The quartz grains coated with Chilean and Namibian salt produced slightly different results. While there was significant glassy precipitation, no single vesicles occurred on the quartz grains, yet cracks [27] occurred on the quartz treated with Chilean salt and extensive vesicular structure features occurred on the quartz treated with Namibian salt.

\subsection{Experiment 7}

The last experiment in this series was constructed to determine whether soil or sediment $\mathrm{pH}$ played any part in affecting the critical temperature of quartz grain surface texture modification. Different types of soil were used (peat $\mathrm{pH} 3.24$, topsoil $\mathrm{pH} 6.51$ and limed topsoil $\mathrm{pH}$ 7.34). The soil samples were washed to test the $\mathrm{pH}$ and conductivity, and quartz grains (similar to those used in experiment 6) were then covered by each solution and placed in an oven for 30 minutes at $100^{\circ} \mathrm{C}$ to evaporate the excess water and precipitate minerals in the soil solutions onto the quartz grains. The quartz-soil mixtures were then subjected to temperatures of $800^{\circ} \mathrm{C}, 900^{\circ} \mathrm{C}$ and $1000^{\circ} \mathrm{C}$.

It is pertinent to note that during these experiments, upon the removal of samples from the furnace, the 'catalysts' had all undergone physical change. All the peat burnt off leaving very clean looking quartz grains. The limed soil underwent only minor 
change, with the soil colour appearing darker after heating. The topsoil became pink, leaving a pink residue on the quartz grains after heating. Significantly, no heatinduced changes to the quartz grain surfaces were observed at $800^{\circ} \mathrm{C}, 900^{\circ} \mathrm{C}$ or $1000^{\circ} \mathrm{C}$. Therefore, $\mathrm{pH}$ does not appear to have any effect on the modification of quartz grains due to heat.

\section{Conclusions}

From these experiments, a number of conclusions can be drawn:

1. Under normal conditions, a temperature threshold of $1200^{\circ} \mathrm{C}$ exists for the modification of quartz surface textures.

2. Quartz of different modes of formation demonstrate similar behaviour of a $1200^{\circ} \mathrm{C}$ threshold for surface texture modification.

3. The heat-induced quartz grain surface textures that are observable at temperatures of $1200^{\circ} \mathrm{C}$ and above include glassy precipitation (snowdrifting), single vesicles and extensive vesicular structures (figures 2, 3, 4 and 7). These features are similar to those identified in natural pyroclastic rocks [27].

4. Potential 'catalysts' such as clothing (cotton, denim and lycra), and substances present in motor vehicles (engine oil, car body paint, rubber, footwell carpet, and plastic) do not appear to have any effect on this threshold.

5. Vehicular fires (of small vehicles in this experimental study) do not achieve the temperature threshold of $1200^{\circ} \mathrm{C}$ and so quartz grains recovered from such fires do not appear to have any heat induced modifications.

6. The $\mathrm{pH}$ of a soil/sediment does not appear to have any effect on the threshold temperature of quartz surface texture modification.

7. The presence of salt does appear to act to depress the temperature at which heat-induced quartz surface textures are generated from $1200^{\circ} \mathrm{C}$ to $900^{\circ} \mathrm{C}$.

8. Salt does not have a uniform effect on quartz. Glassy precipitation (snowdrift) features are common to all kinds of salt tested, but single vesicles, extensive vesicular structures and cracks only occur in the presence of specific types of salt compositions. 
It is well documented that when soil/sediment samples are subjected to high temperatures, significant modifications will occur to the colour, mineralogy, particle size, chemistry, organic content and biological characteristics of the sample. Quartz grains are one of the only components of a soil left after exposure to severe burning, alongside mica and feldspar grains [23], and therefore these findings have significant implications for the use of quartz grain surface texture analysis in forensic investigations. Temperature measurements taken from deliberately torched cars have shown that the maximum temperature reached in the car was $810^{\circ} \mathrm{C}$ in the footwell, whilst wheel arch temperatures ranged from $285-735^{\circ} \mathrm{C}$. Therefore, the surface textures of quartz grains recovered from burning vehicles are highly likely to be unmodified by the heat (even when salt is present) and so can be considered suitable for forensic comparison with quartz grains that have not been heated. However, caution should be exercised when analysing quartz from marine or saline environments, as the presence of salt may affect the surface textures if the temperature reached the critical threshold of $900^{\circ} \mathrm{C}$. It is noted that these heat-induced textures are highly recognisable and characteristic, and therefore, only if they are present should the analysis and interpretation of quartz grain surface textures be adjusted accordingly.

The usual caveat of any forensic analytical technique applies in this case. As part of a suite of independent analytical techniques, this technique has the potential to be highly informative, reliable and accurate in making comparisons between forensic samples, and identifying where exclusion of a sample is possible.

\section{Aknowledgements}

The authors would like to acknowledge discussion and comments with Chris Jackson, Dave Banfield and Matthew Morgan. RM acknowledges financial support from the Bruce, Julia and Mortimer May Senior Scholarship at Hertford College Oxford. ML acknowledges help received from Paula Taylor, Terry Westlake and Sam Shaw University of Oxford, Division Officer Pat Cox for assistance in the car fires and Guy Roberts for access to the car fire data (Morton in Marsh, Forensic Arson Investigation Course).

\section{References}


[1]Krinsley,D. H. and Doornkamp, J. C. 1973 Atlas of quartz sand surface textures. Cambridge University Press

[2]Margolis, S. V. and Krinsley, D. H. 1974 Processes of formation and environmental occurrence of microfeatures on detrital quartz grains'. American Journal of Science 274: 449-464

[3]Whalley, W. B. 1978 Scanning Electron Microscopy in the Study of Sediments. A Symposium pp212-226. Geo Abstracts: Norwich, England.

[4]Bull, P. A. 1981 Environmental reconstruction by electron microscopy. Progress in Physical Geography 5: 368-397

[5]Bull, P. A.,Whalley, W. B. \& Magee, A. W. (1985) An annotated bibliography of environmental reconstruction by SEM 1962-1985. British Geomorphological Research Group. Technical Bulletin No. 5

[6]Bull, P. A. 2000 The Paviland Caves, Gower: The cave sediments. - In AldhouseGreen, S.(ed): Paviland Cave and the 'Red Lady'. A definitive report. Western Academic and Specialist Press Limited, Bristol, UK.

[7]Goudie, A. S., Parker, A. G., Bull, P. A., White, K. \& Al-Farraj, A. 2000 Desert Loess in Ras Al Kamaimah, United Arab Emirates. Journal of Arid Environments 46: 123-135.

[8]Middleton, N. J., Betzer, P. R. and Bull, P. A. 2001 Long-range transport of 'giant' aeolian quartz grains: linkage with discrete sedimentary sources and implications for protective particle transfer. Marine Geology 177: 441-417.

[9]Morgan, R. M., Bull, P. A. and Paskoff, R. 2005 Origin of the Cerro El Dragón coastal dune, Iquique, Atacama desert, Chile. Zeitschrift fur geomorphologie 49(2): 167-182

[10]Bull, P. A. and Morgan, R. M. 2006 Sediment Fingerprints. Science and Justice 46 (2): 107-124

[11]Sugita, R. and Marumo, Y. 2001 Screening of soil evidence by a combination of simple techniques: validity of particle size distribution. Forensic Science International 122: 155-158

[12]Junger, E. P. 1996 Assessing the unique characteristics of close-proximity soil samples: just how useful is soil evidence? Journal of Forensic Science 41(1): 27-34 [13]Cox, R. J. et al. 2000 Forensic analysis of soil organic by FTIR. Forensic Science International 108(2)107-116 
[14]Thornton and McLaren 1975 Enzymatic characterisation of soil evidence.

Journal of Forensic Sciences 20: 674 - 692

[15]USGS 2000 Effects of fire in the Northern Great Plains. Effects of fire on soil nutrients and minerals. Available at http://www.npwrc.usgs.gov/resource/2000/fire/soilnuts.htm [16]Palese, M. A., Giovannini, G., Lucchesi, S., Dumontet, S. and Perucci, P. 2004 Effect of fire on soil C, N and microbial biomass. Agonomie 24: 47-53

[17]Walls, H.J. 1968 Forensic Science. London: Sweet and Maxwell.

[18]Sugita, R. and Marumo, Y. 1996 Validity of colour examination for forensic soil identification. Forensic Science International 83: 201-210

[19]Chazottes,V., Brocard, C. and Peyrot, B. 2004 Particle size analysis of soils under simulated sceneof crime conditions: the interest of multivariate analyses. Forensic Science International 140, (2-3) :159-166

[20]Pye, K. and Blott, S. J. 2004 Particle size analysis of sediments, soils and related particulate materials for forensic purposes using laser granulometry. Forensic Science International 144 (1):19-27

[21]Croft, D. J. and Pye, K. 2004 Multi-technique comparison of source and primary transfer soil samples: and experimental investigation. Science and Justice 44 (1):2128

[22]Sertsu, S. M. and Sanchez, P. A. 1978 Effects of heating on some changes in soil properties in relation to an Ethiopian land management. Soil Sci Soc Am J 42: 940944

[23]Ulery, A. L., Graham, R. C. 1993 Forest fire effects on soil colour and texture. Soil Sci Soc America J 57:135-140

[24]Ulery, A. L., Graham, R. C. and Bowen 1996 Forest fire effects on soil phyllosilicates in California. Soil Sci Soc Am J 60: 309-315

[25]Iglesias, T., Cala, V. and Gonzalez, J. 1997 Mineralogical and chemical modifications in soil affected by a forest fire in the Mediterranean area. The Science of the total Environment 204: 89-96

[26]McKenzie, N. 2003 Fire-induced changes to soil available at http://www.catchment.crc.org.au/bushfire/downloads/impact_of_fire_on_soil.pdf [27]Heiken, G. and Wohletz, K. 1985 Volcanic Ash. University of California Press [28]Folk, R. L., 1974, Petrology of sedimentary rocks: Austin, Texas, Hemphill publishing Co. (182pp) 


\section{List of Figures}

Figure 1 Changes in soil and plant material after heating (from McKenzie 2003 [26])

Figure 2 SEM micrograph of quartz grain surface exhibiting the developing of vugs and single vesicles at experimental temperature of $1200^{\circ} \mathrm{C}$.

Figure 3 SEM micrograph of quartz grain surface exhibiting crack propagation at experimental temperatures of $1200^{\circ} \mathrm{C}$.

Figure 4 SEM micrograph of quartz grain surface exhibiting glassy precipitation ('snowdrifting') at experimental temperatures of $1200^{\circ} \mathrm{C}$.

Figure 5 SEM micrograph of quartz grain from soil A before heat treatment

Figure 6 SEM micrograph of quartz grain from soil A after heating to $900^{\circ} \mathrm{C}$ (note no textural difference to that found in figure 5).

Figure $7 \mathrm{SEM}$ micrograph of quartz grain from soil A after heating to $1200^{\circ} \mathrm{C}$ (note the temperature induced modifications of extensive vesicular structure).

Figure 8 Table summarising maximum temperature $\left({ }^{\circ} \mathrm{C}\right)$ reached during experimentation in each location for each vehicle.

* see Figure 9 for detailed thermograph

**The wheel arches of the Escort were unaffected by the flames due to the seat of the fire being in the rear interior of the vehicle.

Figure 9 Thermograph of temperatures $\left({ }^{\circ} \mathrm{C}\right)$ reached during the burning of the Ford Sierra XR4i vehicle. Temperatures recorded every 3 seconds.

Figure 10 Table summarising the experiments undertaken for quartz of different modes of formation and provenance.

Figure 11 Table summarising the results derived from experiment 6 investigating the effect of salt $(\mathrm{NaCl})$ on the critical temperature for quartz grain surface texture modification.

Figure 12 Table summarising the results derived from experiment 6 investigating the effect of different salt compounds on the critical temperature for quartz grain surface texture modification. 


\begin{tabular}{|c|c|c|}
\hline $\begin{array}{l}\text { Dominant } \\
\text { type of } \\
\text { change } \\
\end{array}$ & $\begin{array}{l}\text { Temperature } \\
\left({ }^{\circ} \mathrm{C}\right)\end{array}$ & Change to the soil/sediment \\
\hline \multirow[t]{6}{*}{ Physical } & $>1200$ & Loss of calcium as gas \\
\hline & 950 & Clay minerals converted to different phases \\
\hline & 600 & Maximum loss of potassium and phosphorus \\
\hline & 540 & Little residual nitrogen or carbon left \\
\hline & 420 & $\begin{array}{l}\text { Water lost from within clay minerals causing change in } \\
\text { type }\end{array}$ \\
\hline & 400 & Organic matter carbonized \\
\hline \multirow[t]{4}{*}{ Chemical } & 300 & $\begin{array}{l}\text { Maximum amino acid nitrogen released } \\
\text { Loss of sulphur and phosphorous begins } \\
\text { Organic matter charred }\end{array}$ \\
\hline & 200 & $\begin{array}{l}\text { Water repellence caused by distillation of volatiles } \\
\text { Loss of nitrogen commences }\end{array}$ \\
\hline & 125 & Soil sterilization \\
\hline & 70 & High nitrate mineralization \\
\hline \multirow[t]{2}{*}{ Biological } & 50 & Mild sterilisation owing to water loss \\
\hline & $<25$ & Usual soil temperatures \\
\hline
\end{tabular}

Figure 1 Changes in soil and plant material after heating (from McKenzie 2003 [26])

\begin{tabular}{llll}
\hline & Sierra* & Escort & Renault \\
\hline Wheelarches & 285 & $\mathrm{n} / \mathrm{a}^{* *}$ & 725 \\
Footwells & 226 & 476 & 810 \\
\hline
\end{tabular}

Figure 8 Table summarising maximum temperature $\left({ }^{\circ} \mathrm{C}\right)$ reached during experimentation in each location for each vehicle.

* see Figure 9 for detailed thermograph

**The wheel arches of the Escort were unaffected by the flames due to the seat of the fire being in the rear interior of the vehicle. 


\begin{tabular}{|c|c|c|c|}
\hline & Sample & $\begin{array}{l}\text { Experimental } \\
\text { conditions }\end{array}$ & $\begin{array}{l}\text { Grain modification } \\
(\%)\end{array}$ \\
\hline \multirow{8}{*}{$\begin{array}{l}\text { Initial } \\
\text { Experiments }\end{array}$} & Pegmatitic quartz & $900^{\circ} \mathrm{C}$ for 30 minutes & 0 \\
\hline & Metamorphic schist & $900^{\circ} \mathrm{C}$ for 30 minutes & 4 \\
\hline & Aeolian derived quartz & $900^{\circ} \mathrm{C}$ for 30 minutes & 0 \\
\hline & Marine derived quartz & $900^{\circ} \mathrm{C}$ for 30 minutes & 70 \\
\hline & Pegmatitic quartz & $1200^{\circ} \mathrm{C}$ for 30 minutes & 4 \\
\hline & Metamorphic schist & $1200^{\circ} \mathrm{C}$ for 30 minutes & 100 \\
\hline & Aeolian derived quartz & $1200^{\circ} \mathrm{C}$ for 30 minutes & 100 \\
\hline & Marine derived quartz & $1200^{\circ} \mathrm{C}$ for 30 minutes & 100 \\
\hline \multirow{4}{*}{$\begin{array}{l}\text { Subsequent } \\
\text { experiments }\end{array}$} & Pegmatitic quartz & $1200^{\circ} \mathrm{C}$ for 1 hour & 6 \\
\hline & Pegmatitic quartz & $1200^{\circ} \mathrm{C}$ for 2 hours & 2 \\
\hline & Pegmatitic quartz & $\begin{array}{l}\text { Crushed further to } \\
\text { reduce particle size and } \\
\text { subjected to } 1200^{\circ} \mathrm{C} \text { for } \\
30 \text { minutes. }\end{array}$ & 0 \\
\hline & Marine quartz & $\begin{array}{l}\text { Washed and subjected } \\
\text { to } 900^{\circ} \mathrm{C} \text { for } 30 \\
\text { minutes. }\end{array}$ & 4 \\
\hline
\end{tabular}

Figure 10 Table summarising the experiments undertaken for quartz of different modes of formation and provenance.

\begin{tabular}{ccc}
\hline Temperature $\left({ }^{\mathbf{0}} \mathbf{C}\right)$ & Salt present $(\mathbf{Y} / \mathbf{N})$ & $\begin{array}{c}\text { Heat-induced textures } \\
\text { present }\end{array}$ \\
\hline No heat & $\mathrm{N}$ & none \\
\hline 800 & $\mathrm{~N}$ & none \\
\hline 900 & $\mathrm{~N}$ & none \\
\hline 1000 & $\mathrm{~N}$ & none \\
\hline 1100 & $\mathrm{~N}$ & none \\
\hline No heat & $\mathrm{Y}$ & none \\
\hline 800 & $\mathrm{Y}$ & $\begin{array}{c}\text { Glassy precipitation and } \\
\text { single vesicles }\end{array}$ \\
\hline 900 & $\mathrm{Y}$ & $\begin{array}{c}\text { Glassy precipitation and } \\
\text { single vesicles }\end{array}$ \\
\hline 1000 & & Glassy precipitation \\
\hline 1100 & $\mathrm{Y}$ &
\end{tabular}

Figure 11 Table summarising the results derived from experiment 6 investigating the effect of salt $(\mathrm{NaCl})$ on the critical temperature for quartz grain surface texture modification. 


\begin{tabular}{llcccc}
\hline Salt Type & $\begin{array}{l}\text { Temperature } \\
\left({ }^{\circ} \mathbf{C}\right)\end{array}$ & \multicolumn{4}{c}{ Surface texture features (\% of grains) } \\
\cline { 2 - 6 } & $\begin{array}{c}\text { Glassy } \\
\text { precipitation } \\
\text { (snowdrifting) }\end{array}$ & $\begin{array}{c}\text { Single } \\
\text { vesicles }\end{array}$ & $\begin{array}{c}\text { Extensive } \\
\text { vesicular } \\
\text { structure }\end{array}$ & Cracks \\
\hline Table salt & 800 & 0 & 0 & 0 & 0 \\
\cline { 2 - 6 } & 900 & 100 & 93 & 0 & 0 \\
\cline { 2 - 6 } & 1000 & 100 & 93 & 27 & 0 \\
\hline Sea salt & 800 & 0 & 0 & 0 & 0 \\
\cline { 2 - 6 } & 900 & 100 & 73 & 0 & 0 \\
\cline { 2 - 6 } & 1000 & 100 & 87 & 0 & 0 \\
\hline Chilean & 800 & 0 & 0 & 0 & 0 \\
\cline { 2 - 6 } & 900 & 80 & 0 & 0 & 13 \\
\cline { 2 - 6 } & 1000 & 80 & 0 & 0 & 13 \\
\hline Namibian & 800 & 0 & 0 & 0 & 0 \\
\cline { 2 - 6 } & 900 & 87 & 0 & 0 & 0 \\
\cline { 2 - 6 } & 1000 & 87 & 0 & 13 & 0 \\
\hline
\end{tabular}

Figure 12 Table summarising the results derived from experiment 6 investigating the effect of different salt compounds on the critical temperature for quartz grain surface texture modification. 